\title{
Pseudomonas syringae pv. actinidiae survival in point- inoculated kiwifruit vines
}

\author{
Joy L. Tyson*, Michael A. Manning, Kieran D. Mellow and Michelle J. Vergara \\ The New Zealand Institute for Plant \& Food Research Limited, Private Bag 92169, Auckland, \\ 1142, New Zealand \\ *Corresponding author: Joy.Tyson@plantandfood.co.nz
}

\begin{abstract}
The survival and spread over time of Pseudomonas syringae pv. actinidiae (Psa) in point-inoculated kiwifruit vines is poorly understood. Forty-eight 2-year-old vines of Actinidia chinensis var. deliciosa 'Hayward' and A. chinensis var. chinensis 'Hort16A' were inoculated $30 \mathrm{~cm}$ above the crown, either during the active growth (autumn) or dormant (winter) period in two successive years. Vines were cultivated for 3-4 years, after which bacterial isolations were made at intervals along the vines from crown to tip. Psa was found up to $220 \mathrm{~cm}$ above the inoculation point and, in some of the crowns, $30 \mathrm{~cm}$ below the inoculation point. The sites where Psa was found within vines were not always contiguous. Fewer vines of 'Hayward' developed serious symptoms or died than 'Hort16A'; however, more surviving vines of 'Hayward' were Psa-positive than those of 'Hort16A'. Psa was able to survive for at least 4 years in apparently healthy kiwifruit vines. This has implications for the movement of asymptomatic budwood to areas without Psa.
\end{abstract}

Keywords Psa, bacterial canker, systemic migration, enrichment, qPCR, latency.

\section{INTRODUCTION}

Kiwifruitbacterial canker, caused by Pseudomonas syringae pv. actinidiae (Psa), remains the most important disease of Actinidia species in New Zealand. Since the identification of Psa in New Zealand in 2010 (Everett et al. 2011), ongoing research programmes have added substantially to the knowledge of the epidemiology of this pathogen. However, asymptomatic spread and survival of Psa within a host plant over time is not well understood.

Short-term movement of Psa through kiwifruit plants in New Zealand has been previously studied in tissue-cultured plantlets inoculated once at the base, over 2 weeks (Tyson et al. 2017a); in 2-year-old vines inoculated once at a girdle and assessed over 5 months (Tyson et al. 2014); and in mature field vines continuously exposed to natural inoculum and assessed over three seasons (Tyson et al. 2014). Longer-term survival of Psa in kiwifruit vines has been studied in Italy in 2-year-old 'Hort16A' inoculated with a low dose of Psa, and tested for up to 5 years (Minardi et al. 2015). In all of these studies, it was found that Psa was able to become systemic while the vines remained asymptomatic.

This study examines the fate of Psa in vines of two kiwifruit cultivars up to 4 years after being inoculated either during active growth, or during dormancy.

\section{MATERIALS AND METHODS \\ Plant material}

Tissue-cultured plantlets of $A$. chinensis var. chinensis 'Hort16A' and $A$. chinensis var. deliciosa 'Hayward' were raised in a glasshouse in a Psafree area until 2 years of age and approximately $2 \mathrm{~m}$ in height.

Inoculum preparation

Pseudomonas syringae pv. actinidiae isolate cc691 (Psa biovar 3) was used for all inoculations in this 
study and has been deposited in the International Collection of Microorganisms from Plants, Landcare Research, Auckland, New Zealand (ICMP 21746).

For each experiment, the inoculum was grown on King's B medium (KB) (King et al. 1954) for $48 \mathrm{~h}$ at $20^{\circ} \mathrm{C}$, then suspended in bacteriological saline (BS, $0.85 \% \mathrm{NaCl}$ in sterile distilled water) and the concentration adjusted to an optical density of ca. $1.0(600 \mathrm{~nm})$ with an Agilent 8453 spectrophotometer. Aliquots $(100 \mu \mathrm{L})$ of the inoculum was spread over 5 plates containing $\mathrm{KB}$ and, after three days, plate counts were performed to confirm that the inoculum concentration was $10^{9}$ colony forming units $/ \mathrm{mL}(\mathrm{cfu} / \mathrm{mL})$.

\section{Inoculation}

Sets of 2-year-old vines were taken to the Plant \& Food Research Te Puke Research Orchard (TPRO) and inoculated with Psa in May 2013 (active growth), July 2013 (dormancy), May 2014 (active growth) and August 2014 (dormancy).

At each inoculation time, the main stems of 12 vines (six 'Hayward' and six 'Hort16A') were point-inoculated with $0.1 \mathrm{~mL}$ inoculum into a $3-\mathrm{mm}$ diameter hole drilled in the stem $30 \mathrm{~cm}$ above soil level, which was immediately sealed with Parafilm ${ }^{\circledast}$. The Parafilm was removed after $24 \mathrm{~h}$.

After this period, the vines were held in a randomised design in a polythene tunnelhouse to protect from subsequent exposure to natural inoculum. In addition, secondary walls of polythene were constructed to fully enclose the plants within the larger tunnel-house. In an orchard situation, rainfall is essential for inoculum production, inoculum movement and infection of susceptible leaves (Tyson et al. 2017b) so the plants were drip-irrigated into the soil to ensure that no splash (or cross-contamination) was generated between vines.

\section{Assessments and final sampling}

For the first 12 months after inoculation, the vines were monitored fortnightly and thereafter monthly. In November 2017, vines were destructively sampled at up to 11 points along the main stem. Over the 3 or 4 years after inoculation, vines responded in one of five ways:

1. No dieback, initial main stem with inoculation site alive (type 1),

2. Initial main stem died back to below the inoculation site (IS), a new main stem developed one or two buds below the IS (type 2),

3. Initial main stem died back to the crown, and a new main stem developed from the crown (type 3),

4. Initial main stem and crown died, and a new main stem developed from the roots (type 4),

5. Entire vine died (type 5).

A number of the vines died, but all the remaining vines appeared healthy at the final assessment. Plants that were assessed as symptom types 2-4 had produced new shoots that then became the main stem.

Vines of each response type were sampled either along the original main stem (type 1), or along the new main stem (types 2, 3, \& 4). Vines that died over the timeframe of the experiment were tested shortly after they died to confirm the presence of Psa.

In each case, the vines were sampled by removing a $1-\mathrm{cm}$ section of crown or stem with sterile secateurs at the crown, and at 10, 20, 30 $40,50,100,150,200,250$ and $300 \mathrm{~cm}$ up the stem above the crown (or up to its full height).

\section{Isolation and identification}

Each stem section was macerated in 1-4 mL BS, depending on the sample size, and left for $5 \mathrm{~min}$, after which $100 \mu \mathrm{L}$ of the resulting suspension was spread across a Petri plate containing an agar medium semi-selective for Pseudomonas syringae. This medium was a slight modification of KBC (Mohan \& Schaad 1987), using sucrose nutrient medium as the base instead of King's B medium (Tyson et al. 2016).

The isolation plates were incubated at $20^{\circ} \mathrm{C}$ for $72 \mathrm{~h}$ and then visually assessed for bacterial growth. DNA extraction, and qPCR conditions and analysis, were as described by Tyson et al. (2012), using the primers PsaF3 and PsaR4 
developed by Rees-George et al. (2010). In this study, a Cp (crossing point or threshold) value below 30 was interpreted as a Psa positive result, $30-35$ as a weak positive, and a Cp value above 35 as a negative result.

\section{RESULTS}

Over the experimental period, $8 \%(2 / 24)$ of the 'Hayward' vines and 25\% (6/24) of the 'Hort16A' vines died. All vines that died tested positive for Psa.

Three or four years after inoculation, Psa had a sporadic distribution within the remaining inoculated vines, and was found up to $250 \mathrm{~cm}$ above the soil ( $220 \mathrm{~cm}$ above the IS) as well as in the crown (Fig. 1). Of the vines that survived, 55\% $(12 / 22)$ of the 'Hayward' vines tested positive for Psa compared with 33\% (6/18) of the 'Hort16A' vines (Table 1, Table 2). There was no obvious difference in the numbers of surviving Psapositive vines that were inoculated during active growth and those inoculated during dormancy.

Most (22/24) of the vines of 'Hort16A' developed dieback of the main stem to below the inoculation point or to the crown or roots, or died (symptom types 2-5) compared with 12/24 vines of 'Hayward' (Table 2). Psa was not found in stems that had grown from the roots of vines of 'Hort16A' that had died back to below the crown.

\section{DISCUSSION}

This study has found that Psa was able to move in the tissues of point-inoculated kiwifruit vines and survive within the plants for up to 4 years.

Psa was found from the crowns to a height of $250 \mathrm{~cm}$ above ground level, although the sites where Psa was found were rarely contiguous. Given the irregular detection of Psa in the tissues, and the widely spaced isolation sites, Psa may have been present in the untested tissues. It is also possible that the areas from which Psa was not recovered represent a bacterial population below the limits of detection. The discontinuous nature of Psa within the vines may also indicate that there are more suitable sites for the bacterium to reside in a latent state, or that populations of Psa have become fragmented during plant growth.
There is little information on this area; however, Gao et al. (2016) has used a GFP-labelled strain of Psa to show that the bacterial cells colonise both phloem and xylem vessels.

To ensure that the vines were protected from subsequent Psa infections, they were kept throughout the trial in a polythene greenhouse. It is possible high temperatures (over $30^{\circ} \mathrm{C}$ ) during the summers of the trial affected survival rates of the bacterium within the plants.

The green kiwifruit cultivar 'Hayward' is considered to be tolerant of Psa, while 'Hort 16A' is considered highly susceptible (Hoyte et al. 2015; Tyson et al. 2017a). As expected, fewer 'Hayward' vines died compared with 'Hort16A' vines in the current study. Also, 'Hayward' vines were less likely to develop serious symptoms, e.g. major dieback to the inoculation point or the crown, or death of the entire vine. However, the surviving vines of 'Hayward' were more likely to carry Psa within the vine. None of the vines of 'Hort16A' that died to below the crown and re-grew from the roots carried Psa in the tissue $(0 / 5)$ and there is an indication from this work that extensive dieback allowed the vine to halt movement of the bacterium.

At the final assessment, all surviving vines were apparently healthy. Vines that had died back to varying degrees had all produced new canes that then became the main stem. Psa was able to survive in a latent state for up to 4 years in kiwifruit vines of a tolerant cultivar ('Hayward') and in a highly susceptible cultivar ('Hort16A').

The trial was designed to contain the vines from the risk of further infection by natural inoculum, so the authors are confident that the detection of Psa in vines several years after pointinoculation was not due to subsequent infection by natural inoculum. In addition, none of the susceptible kiwifruit vines being continuously grown adjacent to the inoculated vines showed symptoms of Psa over the 4 years of the trial. 


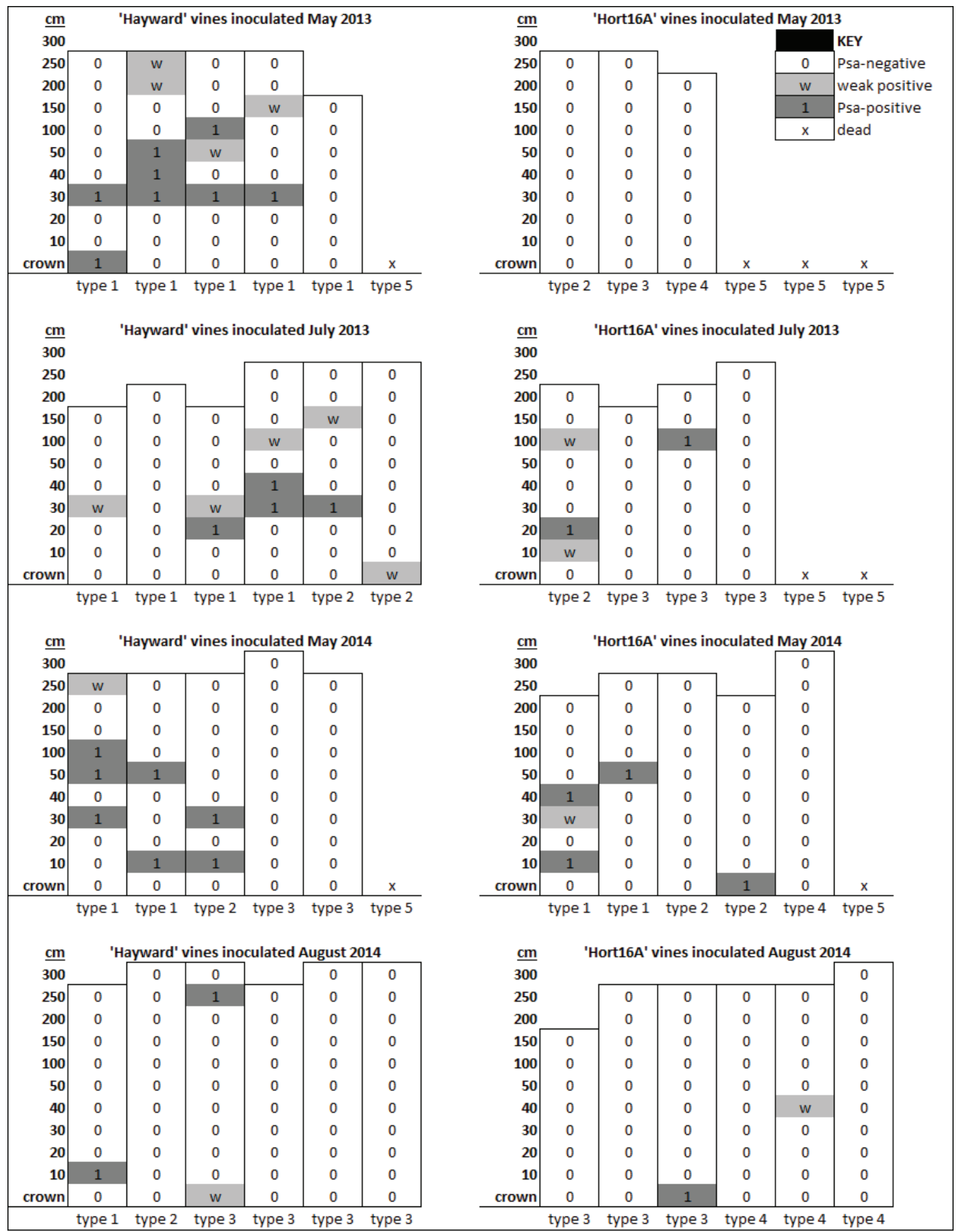

Figure 1 Detection of Pseudomonas syringae pv. actinidiae (Psa) within the tissues of kiwifruit vines after 3 or 4 years after point inoculation. Each column is a separate vine, final symptom types are given beneath each column. 
Table 1 Number of vines of each kiwifruit cultivar and each inoculation time that tested positive or negative for Pseudomonas syringae pv. actinidiae (Psa) or died during the course of the trial.

\begin{tabular}{lll}
\hline Inoculation year & 'Hayward' & 'Hort16A' \\
\hline 2013 - active growth & 4 Psa positive & 0 Psa positive \\
& 1 Psa negative & 3 Psa negative \\
& 1 dead (Psa positive) & 3 dead (Psa positive) \\
\hline 2013 - dormant & 3 Psa positive & 2 Psa positive \\
& 3 Psa negative & 2 Psa negative \\
& 0 dead & 2 dead (Psa positive) \\
\hline 2014 - active growth & 3 Psa positive & 3 Psa positive \\
& 2 Psa negative & 2 Psa negative \\
& 1 dead (Psa positive) & 1 dead (Psa positive) \\
\hline $2014-$ dormant & 2 Psa positive & 1 Psa positive \\
& 4 Psa negative & 5 Psa negative \\
& 0 dead & 0 dead \\
\hline
\end{tabular}

Table 2 Percentage of vines from all inoculation sets (2013 and 2014) in each symptom type that tested positive for Pseudomonas syringae pv. actinidiae (actual numbers are provided in parentheses).

\begin{tabular}{llrrrr}
\hline $\begin{array}{l}\text { Symptom } \\
\text { type }\end{array}$ & Description & \multicolumn{3}{c}{$\begin{array}{c}\text { \% Psa-positive vines in each } \\
\text { symptom type }\end{array}$} \\
& & \multicolumn{3}{c}{ 'Hayward' } & 'Hort16A' \\
\hline type 1 & no dieback & 75 & $(9 / 12)$ & 100 & $(2 / 2)$ \\
type 2 & dieback to below inoculation point & 40 & $(2 / 5)$ & 50 & $(2 / 4)$ \\
type 3 & dieback to crown & 40 & $(2 / 5)$ & 29 & $(2 / 7)$ \\
type 4 & dieback to roots & - & $(0 / 0)$ & 0 & $(0 / 5)$ \\
type 5 & death & 100 & $(2 / 2)$ & 100 & $(6 / 6)$ \\
\hline & & $\mathbf{6 3}$ & $\mathbf{( 1 5 / 2 4 )}$ & $\mathbf{5 0}$ & $\mathbf{( 1 2 / 2 4 )}$ \\
\hline
\end{tabular}

\section{CONCLUSION}

The presence of Psa in visibly healthy vines has implications for the movement of asymptomatic budwood to areas without Psa.

\section{ACKNOWLEDGEMENTS}

We would like to thank Carol Middleditch for technical assistance and TPRO staff for the longterm use and management of the greenhouse space, particularly Nicola Mauchline and Kirsten Hoeata.

\section{REFERENCES}

Everett KR, Taylor RK, Romberg MK, ReesGeorge J, Fullerton RA, Vanneste JL, Manning MA 2011. First report of Pseudomonas syringae pv. actinidiae causing kiwifruit bacterial canker in New Zealand. Australasian Plant Disease Notes 6: 67-71.

Gao X, Huang Q, Zhao Z, Han Q, Ke X, Qin H, Huang L 2016. Studies on the infection, colonization, and movement of Pseudomonas syringae pv. actinidiae in kiwifruit tissues using a GFPuv-labeled strain. PLoS One 11(3): e0151169. 
Hoyte S, Reglinski T, Elmer P, Mauchline N, Stannard K, Casonato S, Chee AA, Parry F, Taylor J, Wurms K and others 2015. Developing and using bioassays to screen for Psa resistance in New Zealand kiwifruit. Acta Horticulturae 1095: 171-180.

King EO, Ward MK, Raney DE 1954. Two simple media for the demonstration of pyocyanin and fluorescin. Journal of Laboratory and Clinical Medicine 44(2): 301-307.

Minardi P, Ardizzi S, Lucchese C, Bertaccini A 2015. Latent infection by Pseudomonas syringae pv. actinidiae in Actinidia chinensis cv. Hort16A asymptomatic plants: five years of survival and colonization of a mutant virulent strain. II International Psa Symposium. Pp. 19.

Mohan SK, Schaad NW 1987. An improved agar plating assay for detecting Pseudomonas syringae pv. syringae and P. s. pv. phaseolicola in contaminated bean seed. Phytopathology 77(10): 1390-1395.

Rees-George J, Vanneste JL, Cornish DA, Pushparajah IPS, Yu J, Templeton MD, Everett KR 2010. Detection of Pseudomonas syringae pv. actinidiae using polymerase chain reaction (PCR) primers based on the 16S-23S rDNA intertranscribed spacer region and comparison with PCR primers based on other gene regions. Plant Pathology 59(3): 453-464.
Tyson JL, Rees-George J, Curtis CL, Manning MA, Fullerton RA 2012. Survival of Pseudomonas syringae pv. actinidiae on the orchard floor over winter. New Zealand Plant Protection 65: 25-28.

Tyson JL, Curtis CL, Manning MA, Rees-George J, Snelgar WP, Blattmann P 2014. Systemic movement of Pseudomonas syringae pv. actinidiae in kiwifruit vines in New Zealand. New Zealand Plant Protection 67: 41-47.

Tyson JL, Curtis CL, Manning MA, Dobson SJ, McKenna CE 2016. Preliminary investigations of the risk of plant debris as a Pseudomonas syringae pv. actinidiae inoculum source. New Zealand Plant Protection 69: 11-16.

Tyson JL, Vergara MJ, Butler RC, Seelye JF, Morgan ER 2017a. Survival, growth and detection of Pseudomonas syringae pv. actinidiae in Actinidia in vitro cultures. New Zealand Journal of Crop and Horticultural Science: 1-15.

Tyson JL, Manning MA, Curtis CL, Vergara MV, Dobson S, McKenna CE, Beresford RM 2017b. Monitoring Pseudomonas syringae pv. actinidiae inoculum production and infection in New Zealand over a three-year period. IX International Symposium on Kiwifruit. Pp. 116 (Book of abstracts). 